\title{
Phenology of greenhouse thrips (Heliothrips haemorrhoidalis) on kiwifruit vines, shelter trees and alternative host plants
}

\author{
David Logan ${ }^{1, *}$, Christina Rowe², Cathy McKenna², Juliet Herrick² and Paul Rogers ${ }^{2}$ \\ ${ }^{1}$ The New Zealand Institute for Plant and Food Research Ltd, 120 Mt Albert Road, Auckland 1025, New Zealand \\ ${ }^{2}$ The New Zealand Institute for Plant and Food Research Ltd, 412 No. 1 Road, Te Puke 3182, New Zealand \\ *Corresponding author: david.logan@plantandfood.co.nz
}

(Original submission received 6 April 2021; accepted in revised form 22 August 2021)

\begin{abstract}
The greenhouse thrips, Heliothrips haemorrhoidalis is a quarantine pest of kiwifruit. There is a need for reliable information on its phenology in kiwifruit orchards to inform the development of new management options. Numbers of larval, pupal and adult greenhouse thrips were counted on leaves of the two main kiwifruit cultivars Actinidia chinensis var. deliciosa ('Hayward') at two sites at different times and A. chinensis var. chinensis 'Zesy002' at one site. Greenhouse thrips were also counted on leaves of shelter tree species Cryptomeria japonica, and other plants present on kiwifruit orchards, blackberry (Rubus fruticosus s.l.), barberry (Berberis glaucocarpa), and wineberry (Aristotelia serrata) across a number of sites at different times. There was a strong seasonal pattern to the phenology of greenhouse thrips and it was relatively synchronous for all the host plants surveyed. In general, number of greenhouse thrips on foliage increased from January to peak in April or May before declining in late autumn or winter and remaining low until the following January or February. The phenology of greenhouse thrips followed the same seasonal pattern for a variety of host plants found on kiwifruit orchards at sites in the Bay of Plenty across two two-year time periods. Therefore, host species does not appear to be a factor affecting the phenology of thrips. Other, non-host factors such as microclimate may be important drivers of phenology but they require further study. The consistency of the seasonal pattern of relative abundance means that there is a well-defined window to target for thrips management.
\end{abstract}

Keywords horticulture, insect, pest, survey, fruit, foliage

\section{INTRODUCTION}

The greenhouse thrips, Heliothrips haemorrhoidalis Bouché (Thysanoptera: Thripidae), is an adventive polyphagous species first recorded in Palmerston North in 1930, and now widespread in New Zealand (Mound \& Walker 1982). All stages are found on the leaves of a wide range of host plants including native, crop and ornamental species (Zondag 1977; Martin \& Mound 2004). Eggs are kidney-shaped and are inserted by female insects just below the leaf epidermis. There are two larval stages that feed on the leaf epidermis, followed by non-feeding pre-pupal and pupal stages. Adults also feed on the leaf surface, and can live for up to 4 months and potentially lay 60-100 eggs (Rivnay 1935; Chhagan \& Stevens 2007). All greenhouse thrips in New Zealand are females and reproduce by thelytokous parthenogenesis. There are multiple overlapping generations each year with the shortest generation taking c. 7-8 weeks in summer in northern New Zealand based on temperature-dependent development rates (Chhagan \& Stevens 2007).
Greenhouse thrips are production pests of kiwiberry, Actinida arguta (Siebold \& Zucc.) Planch. Ex Miq., 'Hass' avocado, Persea americana Mill., and citrus species in New Zealand (Spiller \& Wise 1982; Blank \& Gill 1997; McKenna et al. 2009). In these crops, greenhouse thrips feed on the outer skin of fruit particularly where there is contact with other fruit or leaves. The resulting scars lead to the downgrading of fruit for market. Feeding by greenhouse thrips is not associated with any loss of production of fruit from the main kiwifruit cultivars Actinidia chinensis var. deliciosa (hereafter referred to as Hayward) and A. chinensis var. chinensis 'Zesy002', but extensive leaf damage can occur when infestations are heavy. As a result, thrips can be dislodged onto fruit during harvest and fruit found with thrips at packing is not sent to some key markets such as Japan, Korea and the USA. This approach is taken because immature thrips found during inspection of imported fruit in those markets trigger fumigation of shipments, a cost which must be met by New Zealand growers. 
Management options to reduce the numbers of greenhouse thrips in kiwifruit crops are limited. There are no sprays recommended for kiwifruit because infestation occurs after fruit-set, when there is a risk of unacceptable spray residues persisting on fruit at harvest. Growers are advised to maintain an open canopy for good airflow and to avoid creating areas of heavy shading that favour greenhouse thrips populations (D. Steven, unpubl.) but new options for management are needed. Knowledge of pest phenology is fundamental to developing management options, for example to anticipate when pests may occur on crops and deciding when intervention is best timed to reduce or prevent damage. In this study, we surveyed leaves of the two main kiwifruit cultivars ('Hayward' and 'Zesy002') and of some common orchard boundary plants. Our aim was to determine when greenhouse thrips were abundant on different host plants on kiwifruit orchards and hence to inform the development of new management options by identifying the potential sources of fruit infestation.

\section{MATERIALS AND METHODS}

\section{Study sites}

Site 1 was an unsprayed orchard block of kiwifruit Actinidia chinensis var. deliciosa ('Hayward') at the Research Orchard of The New Zealand Institute for Plant and Food Research Limited (Plant \& Food Research) at Te Puke that was sampled between 2011 and 2013.

Site 2 was a conventionally managed orchard block of 'Hayward' kiwifruit at a commercial orchard located in the western Bay of Plenty known to have thrips from leaf samples taken in 2016. This site was sampled in 2017 and 2018.

Site 3 was a conventionally managed orchard block of Actinidia chinensis var. chinensis 'Zesy002' kiwifruit on a separate commercial orchard to Site 2 located in the western Bay of Plenty and known to have thrips from leaf samples taken in 2016. This site was sampled in 2017 and 2018. At site 2 and 3 insecticides (e.g. spirotetramat, Bacillus thuringiensis and methoxyfenozide) were applied to the crop before and shortly after flowering in spring and early summer.

Sites 4-7 were roadsides between Te Puke and Rotorua where alternative host plants were sampled.

\section{Thrips identification}

Adult greenhouse thrips were identified morphologically (with pale forewings, body dark brown to black with reticulate head and pronotum, and femora pale-yellow) and habit of feeding on mature leaves (Mound \& Walker 1982; Nakahara et al. 2015). Immature stages were identified based on their association with adult greenhouse thrips, and supporting traits that differentiate them from other species of the same subfamily Panchaetothripinae in New Zealand. These traits were plant host, pupation on leaves rather than soil and absence of faecal spots on the body (Martin 2016, 2017).

\section{Phenology on kiwifruit}

At Site 1, the phenology of larvae, pupae and adult greenhouse thrips on 'Hayward' kiwifruit leaves was determined by sampling 400 leaves each month from November to June during 2011-12 and 2012-13 to coincide with the development of the canopy and fruit. Leaves were picked in groups of 20 from 20 female vines selected by rand om number for row and vine, bagged by vine and counts of greenhouse thrips made in the laboratory with the aid of a microscope on the same or following day.

The phenology of greenhouse thrips at Sites 2 and 3 was determined by sampling leaves at approximately 2-week intervals from January to May 2017 and January to July 2018. At each sampling visit, two kiwifruit leaves were picked from each of the 150 female Hayward and 179 female Zesy002 vines at Sites 2 and 3 respectively. Leaves were placed individually into plastic zip-lock bags and counts of larvae, pupae and adult greenhouse thrips were made in the laboratory on the same or following day.

\section{Phenology on shelter trees}

The foliage of shelter trees, Cryptomeria japonica (cryptomeria), at Sites 2 and 3 was sampled every fortnight from January to May 2017 and from January to December 2018. The border of Site 1 adjacent to 'Hayward' vines consisted of mixed species including a short shelter row of willows, Salix sp., and a plantation of eucalypts and was not sampled. On each sample date, an approximately $30-\mathrm{cm}$ long cryptomeria branch tip was removed from 20 sample points, each at least $10 \mathrm{~m}$ apart, from shelter trees on two sides of the orchard block at sites 2 and 3. In 2017, foliage was sampled at $1.5 \mathrm{~m}, 3 \mathrm{~m}$ and $5 \mathrm{~m}$ high to determine whether there was an effect of height so that there were 60 separate samples. In 2018, foliage was only sampled from $1.5 \mathrm{~m}$ high (20 samples). Preliminary tests established that visual inspection of the complex foliage of cryptomeria for thrips was too time-consuming to be practical so the following method was used instead. Greenhouse thrips were extracted by first submerging and agitating the foliage in a solution of approximately $0.05 \%$ detergent in hot water (c. $45-55^{\circ} \mathrm{C}$ ) for $10 \mathrm{~s}$. The solution was then poured through a fine mesh cloth (100- $\mu$ m pore) and the number of adult and immature greenhouse thrips on the cloth counted with the aid of a dissecting microscope. In 2018, after extraction of thrips, cryptomeria foliage was oven-dried at $60^{\circ} \mathrm{C}$ for 4 days to determine its dry weight. This enabled counts of extracted thrips to be standardised by dry weight of foliage for each sample from shelter trees.

\section{Phenology on alternative hosts}

The phenology of greenhouse thrips was determined on three alternative host plants commonly found on the boundaries of kiwifruit orchard blocks. These were an introduced weedy species blackberry (Rubus fruticosus s.l.), a naturalised hedgerow species, barberry (Berberis glaucocarpa), and a native tree species, wineberry (Aristotelia serrata). Blackberry were sampled monthly from the boundary of the kiwifruit orchard block at Site 1 
from October 2010 to November 2013 and at four other sites (Sites 4-7) along roadsides between Te Puke and Rotorua from October or November 2011 to August 2013 by picking compound leaves from the upper canopy $(n=80-$ 250). Collection of blackberry leaves was often constrained to edges or short traverses into patches. Barberry and wineberry were sampled monthly from September or October 2012 until September or October 2013 at some of the same sites surveyed for blackberry (barberry: Sites 1 and 4; wineberry: Sites 4, 5 and 7). As barberry and wineberry were less common than blackberry and had relatively sparse foliage, samples consisted of only 30 leaves in total removed from 3-6 plants at each site. All leaves were collected in bags and examined for larvae, pupae and adults on the sample day with the aid of a dissecting microscope.

\section{Data analysis}

The mean and standard deviation for combined counts of adults and immature thrips per leaf per site for all plant hosts except cryptomeria were calculated for each separate growing season (late spring/summer until winter). Cryptomeria samples were not included because of the difference in sampling unit $(30-\mathrm{cm}$ branch tips compared with leaves). The month of the maximum mean count of thrips per leaf per site per fruiting season was also determined. The variance-to-mean ratio was calculated for combined counts of adults and immature thrips for each sample (except cryptomeria) as a simple measure of the uniformity of spread of thrips amongst leaves.

Mean counts for adults and immature thrips for all plant hosts were assessed graphically to identify the general periods of peak abundance. No statistical analysis of the mean counts on different host plants was made as this study was substantially observational and did not include planned comparisons.

A negative binomial Generalised Linear Model was fitted in $\mathrm{R}$ version 3.6.0 (R Core Team 2019) to establish the effect of sample height $(1.5,3$ or $5 \mathrm{~m})$ on the number of greenhouse thrips found in cryptomeria foliage at Sites 2 and 3 in 2017. The model used the standard log link function. Counts of thrips were the combined number of immature and adult thrips for all sample dates.

\section{RESULTS}

Greenhouse thrips were present on leaves of kiwifruit, cryptomeria, blackberry, barberry and wineberry (Table 1, Figures 1, 2 and 3). Peak abundance for combined counts of larvae, pupae and adults amongst all combinations of fruiting season (spring/summer until winter) and sites occurred in either April or May (Table 1). Mean and maximum densities of thrips on leaves varied between plant species (Table 1) although direct comparison is not appropriate due to differences in leaf size. There was also large variability in mean densities between years and sites for the same plant species (Table 1). For example, mean densities each year ranged from 0.4 to 13 thrips per leaf on blackberry at Site 4 and site 1 respectively (Table 1). The distribution of counts on leaves tended to be right-skewed: samples from most dates (70, 82, 93 and $93.5 \%$ of samples for wineberry, barberry, blackberry and kiwifruit, respectively) had variance-to-mean ratios greater than 1 , indicating overdispersion. This result is likely due to the colonial nature of greenhouse thrips.

\section{Phenology on kiwifruit}

On kiwifruit leaves, densities of greenhouse thrips increased from near zero during late spring and early summer to reach their highest densities in late autumn and early winter. This pattern occurred at Site 1 in 2012 and 2013 and at Sites 2 and 3 in 2017 and 2018 (Figure 1a) even though these sites were at different locations and were managed differently. There was also no clear difference in thrips phenology between kiwifruit varieties (Sites 2 and 3) although some differences in insect density occurred (Figure 1). The phenology of larvae and pupae was generally similar to that of adults except in the first sample period (2011-2012) at Site 1 when adult numbers peaked first (Figure 1). Densities of larvae, pupae and adults on leaves declined during late autumn and winter.

\section{Phenology on shelter trees}

Adult and immature greenhouse thrips were found in cryptomeria foliage at both Sites 2 and 3 in 2017 and 2018 (Figure 2). The phenology was generally similar to that on kiwifruit leaves in the adjacent orchard block (Figure 1b and c). There was a noticeable increase of thrips on shelter foliage and on kiwifruit leaves from mid-February until April, although more variably so compared with kiwifruit. After that, thrips numbers on cryptomeria foliage declined and, based on one complete year of sampling in 2018, remained low at least until December. Shelter was trimmed at Sites 2 and 3 in late January 2017 and early February 2018 and this may have had an effect on the number of thrips found. There was no effect of sample height (1.5, 3 or $5 \mathrm{~m}$ ) on the density of greenhouse thrips found in cryptomeria foliage $(p>0.05)$.

\section{Phenology on alternative hosts}

The phenology of greenhouse thrips on barberry, blackberry and wineberry between 2011 and 2013 was similar to that found on kiwifruit over the same period and also the later period of 2017-2018 on cryptomeria and on kiwifruit i.e. a peak in autumn and a tendency for low numbers to be present in winter and summer (Figure 3). Relatively high densities of adults persisted for longer on blackberry leaves at Site 1 in comparison with other sites. There was a second peak of immature thrips on blackberry at Site 1 , and to a certain extent, wineberry at Site 6 , when densities of adults were relatively low in spring (Figure 3).

\section{DISCUSSION}

The aim of this study was to determine when greenhouse thrips were abundant on kiwifruit compared with other host plants on kiwifruit orchards, and hence to identify potential sources of fruit infestation. This work involved sampling a small number of sites over two two-year time periods to assess general trends in seasonal abundance. 
Table 1 Densities of combined counts of larvae, pupae and adult greenhouse thrips, Heliothrips haemorrhoidalis, on leaves of selected host plants present in kiwifruit orchards or roadside sites near orchards, and the month when highest densities for found. SD, one standard deviation.

\begin{tabular}{|c|c|c|c|c|c|c|}
\hline $\begin{array}{l}\text { Plant host } \\
\text { (Site) }\end{array}$ & $\begin{array}{l}\text { Sample period } \\
\text { (Months) }\end{array}$ & $\begin{array}{l}\text { Start and end dates } \\
\text { (Month \& } \\
\text { 2-digit year) }\end{array}$ & $\begin{array}{l}\text { No. Samples } \\
\text { (Leaves/sample) }\end{array}$ & $\begin{array}{l}\text { Mean density } \\
\pm \text { SD }\end{array}$ & $\begin{array}{l}\text { Max. density } \\
\pm \text { SD }\end{array}$ & $\begin{array}{l}\text { Month of } \\
\text { max. } \\
\text { density }\end{array}$ \\
\hline \multirow[t]{2}{*}{ Kiwifruit (1) } & 8 & Nov 11-Jun 12 & $8(400)$ & $0.3 \pm 1.9$ & $1.1 \pm 2.6$ & April \\
\hline & 8 & Nov 12-Jun 13 & $8(400)$ & $0.3 \pm 1.8$ & $0.9 \pm 3.7$ & April \\
\hline \multirow[t]{2}{*}{ Kiwifruit (2) } & 5 & Jan 17-May 17 & $10(300)$ & $1.9 \pm 6.1$ & $4.4 \pm 11.4$ & April \\
\hline & 7 & Jan 18-Jul 18 & $13(300)$ & $3.4 \pm 9.3$ & $12.6 \pm 19.3$ & April \\
\hline \multirow[t]{2}{*}{ Kiwifruit (3) } & 5 & Jan 17-May 17 & $10(358)$ & $6.6 \pm 14.3$ & $21.3 \pm 25.0$ & April \\
\hline & 6 & Jan 18-Jun 18 & $12(358)$ & $9.3 \pm 23.6$ & $39.4 \pm 50.5$ & April \\
\hline \multirow[t]{3}{*}{ Blackberry (1) } & 12 & Oct 10-Sep 11 & $12(250)$ & $7.8 \pm 18.9$ & $16.6 \pm 20.3$ & May \\
\hline & 12 & Oct 11-Sep 12 & $12(160$ or 200$)$ & $13.0 \pm 34.2$ & $18.2 \pm 32.8$ & May \\
\hline & 11 & Oct 12-Aug 13 & $11(160)$ & $8.5 \pm 22.0$ & $61.7 \pm 62.0$ & April \\
\hline \multirow[t]{2}{*}{ Blackberry (4) } & 12 & Oct $11-$ Sep 12 & $12(160$ or 240$)$ & $0.5 \pm 3.4$ & $0.7 \pm 1.8$ & April \\
\hline & 11 & Oct 12-Aug 13 & $11(160)$ & $0.4 \pm 2.5$ & $2.2 \pm 7.9$ & April \\
\hline \multirow[t]{2}{*}{ Blackberry (5) } & 12 & Nov 11 -Oct 12 & $12(80$ or 160$)$ & $2.1 \pm 6.3$ & $4.7 \pm 13.3$ & April \\
\hline & 10 & Nov 12-Aug 13 & $10(80)$ & $1.7 \pm 6.0$ & $9.2 \pm 13.6$ & May \\
\hline \multirow[t]{2}{*}{ Blackberry (6) } & 12 & Nov 11-Oct 12 & $12(80)$ & $1.9 \pm 5.1$ & $13.9 \pm 28.1$ & April \\
\hline & 10 & Nov 12-Aug 13 & $10(80)$ & $3.3 \pm 14.0$ & $6.0 \pm 9.4$ & May \\
\hline \multirow[t]{2}{*}{ Blackberry (7) } & 12 & Nov 11 -Oct 12 & $12(80)$ & $1.3 \pm 2.9$ & $1.6 \pm 11.5$ & May \\
\hline & 10 & Nov 12-Aug 13 & $10(80)$ & $1.0 \pm 3.8$ & $4.3 \pm 5.8$ & May \\
\hline Barberry (1) & 14 & Sep 12 -Oct 13 & $14(30)$ & $1.0 \pm 2.5$ & $4.1 \pm 5.7$ & April \\
\hline Barberry (4) & 14 & Sep 12 -Oct 13 & $14(30)$ & $1.4 \pm 4.2$ & $8.8 \pm 8.8$ & May \\
\hline Wineberry (4) & 13 & Oct $12-0$ ct 13 & $13(30)$ & $0.4 \pm 2.1$ & $2.0 \pm 5.6$ & May \\
\hline Wineberry (5) & 13 & Sep 12-Sep 13 & $13(30)$ & $0.3 \pm 1.7$ & $1.8 \pm 5.1$ & May \\
\hline Wineberry (7) & 14 & Sep 12-Oct 13 & $14(30)$ & $0.6 \pm 1.8$ & $1.8 \pm 2.8$ & May \\
\hline
\end{tabular}

The phenology of greenhouse thrips on foliage followed a strong seasonal pattern and was relatively synchronous for all the host plants surveyed (kiwifruit, the common shelter species Cryptomeria japonica and the non-crop host plants blackberry, wineberry and barberry). For the periods studied, numbers of greenhouse thrips on foliage generally increased from January to peak in April or May before declining in late autumn or winter. One exception was Site 1 with blackberries at which a decline in the density of adult greenhouse thrips on leaves was delayed until spring. This finding may have been due to one or more unique site factors such as protection from wind rather than being related to the host plant as the phenology of thrips at the other three blackberry sites was typical of the general pattern. There was a large variation in abundance between host plants, sites and years, the reasons for which are not understood but could include host plant suitability and suitable microclimates created by shade and protection from wind. These factors need further research on a larger number of sites than sampled here.

There is a period in late winter and spring (c. JulyOctober) when greenhouse thrips are absent from kiwifruit vines because there are no leaves. In this study, low numbers of adult greenhouse thrips were found on kiwifruit leaves in the new canopy in January and they probably arrived by flight from nearby shelter or alternative plant hosts. Immature greenhouse thrips were first observed on kiwifruit leaves between mid-January and mid-February in low numbers. They are wingless and less likely to disperse between host plants than adults. Hence much of the distribution of immature thrips probably reflects local reproduction. Allowing for an egg development period of 3-4 weeks at summer air temperatures suggests that adult thrips may first be present in the kiwifruit canopy in December (Chhagan \& Stevens 2007). After mid-February, numbers of both immature and adult greenhouse thrips 

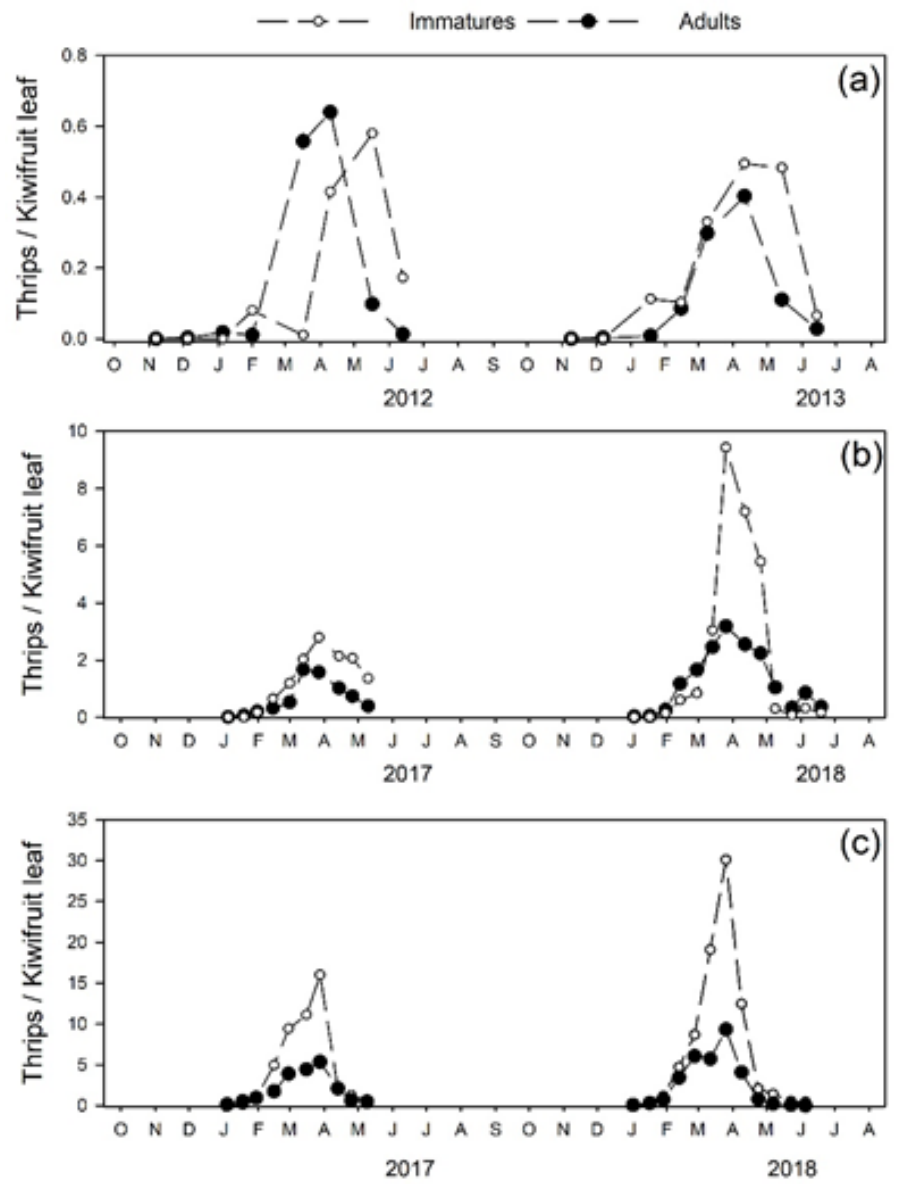

Figure 1 Phenology of adult (solid black symbol) and immature (open symbol) greenhouse thrips (Heliothrips haemorroidalis) on the leaves of 'Hayward' kiwifruit, (a) at Site 1 during 2011-2013 and (b) at Site 2 during 20172018, and on leaves of 'Zesy002' kiwifruit at (c) Site 3 during 2017-2018. Error bars are omitted for clarity.

rapidly increased in a synchronous pattern on all host plants, suggesting that summer (December-February) is a favourable period for egg-laying and survival of larvae. Similarly, the decline in numbers of thrips observed at most sites after April and May suggests that conditions in the autumn became less favourable for oviposition, egg-hatch and/or larval survival. Temperature has a significant effect on reproduction with a lower threshold estimated as $12^{\circ} \mathrm{C}$ (Rivnay 1935, Chhagan \& Stevens 2007) and it is likely that reproduction of greenhouse thrips during autumn and winter is limited. There may also be a negative effect on population growth of greenhouse thrips by the Eulophid larval parasitoid Thripoctenus javae (Girault) as it tends to become more common in autumn; however, this has not been confirmed in recent surveys (Christina Rowe, unpubl.).

Managing populations of greenhouse thrips in the vicinity of crops is likely to be a key component of any future management plan. In particular, cryptomeria shelter trees bordering orchard blocks are probably the most important sources of thrips infesting kiwifruit. Other shelter tree species known to host greenhouse thrips such as Pinus radiata (Spiller \& Wise 1982) and weeds such as blackberry
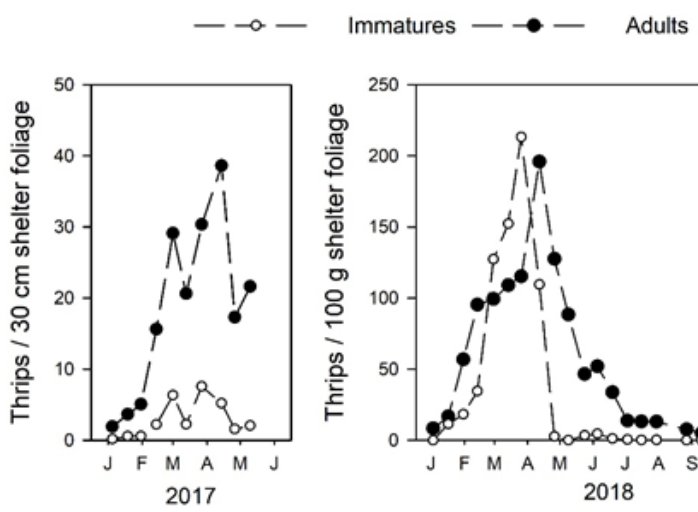

(a)

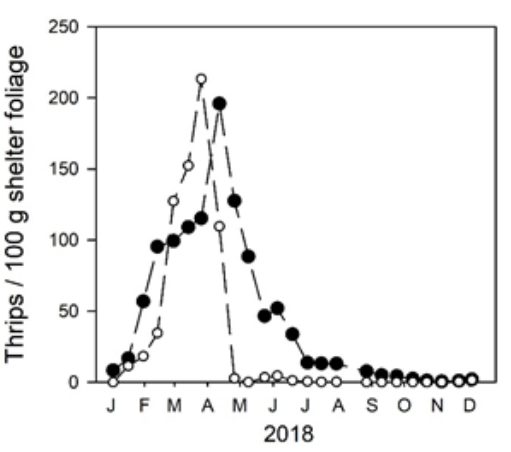

(b)
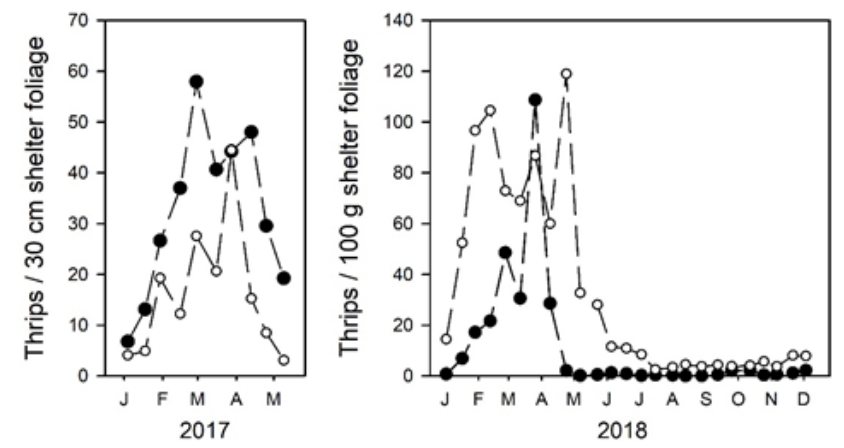

Figure 2 Phenology of adult (solid black symbol) and immature (open symbol) greenhouse thrips (Heliothrips haemorroidalis) on the common shelter species Cryptomeria japonica at two commercial kiwifruit orchards in the Bay of Plenty in 2017 and 2018: (a) orchard Site 2 and (b) orchard Site 3 . Note that different methods were used to assess thrips density on shelter foliage in each year.

are also potential sources of thrips where they occur. The application of an insecticide to the crop and to alternative host plants is one option for management. Pyrethrum, which is applied to kiwifruit after fruitset for managing other pests, has been effective in recent trials against greenhouse thrips, and a sampling plan for kiwifruit leaves is being developed to inform spray timing (C. McKenna, unpubl.).

\section{CONCLUSIONS}

The phenology of greenhouse thrips followed the same seasonal pattern for a variety of host plants found on kiwifruit orchards at a small number of sites in the Bay of Plenty across two two-year time periods. Therefore, host species does not appear to be a factor affecting the phenology of thrips. Other non-host factors such as microclimate may be important drivers of phenology but they require further study. The consistency of the pattern of abundance over the two time periods studied indicates that there is likely to be a welldefined window to target kiwifruit for thrips management. 

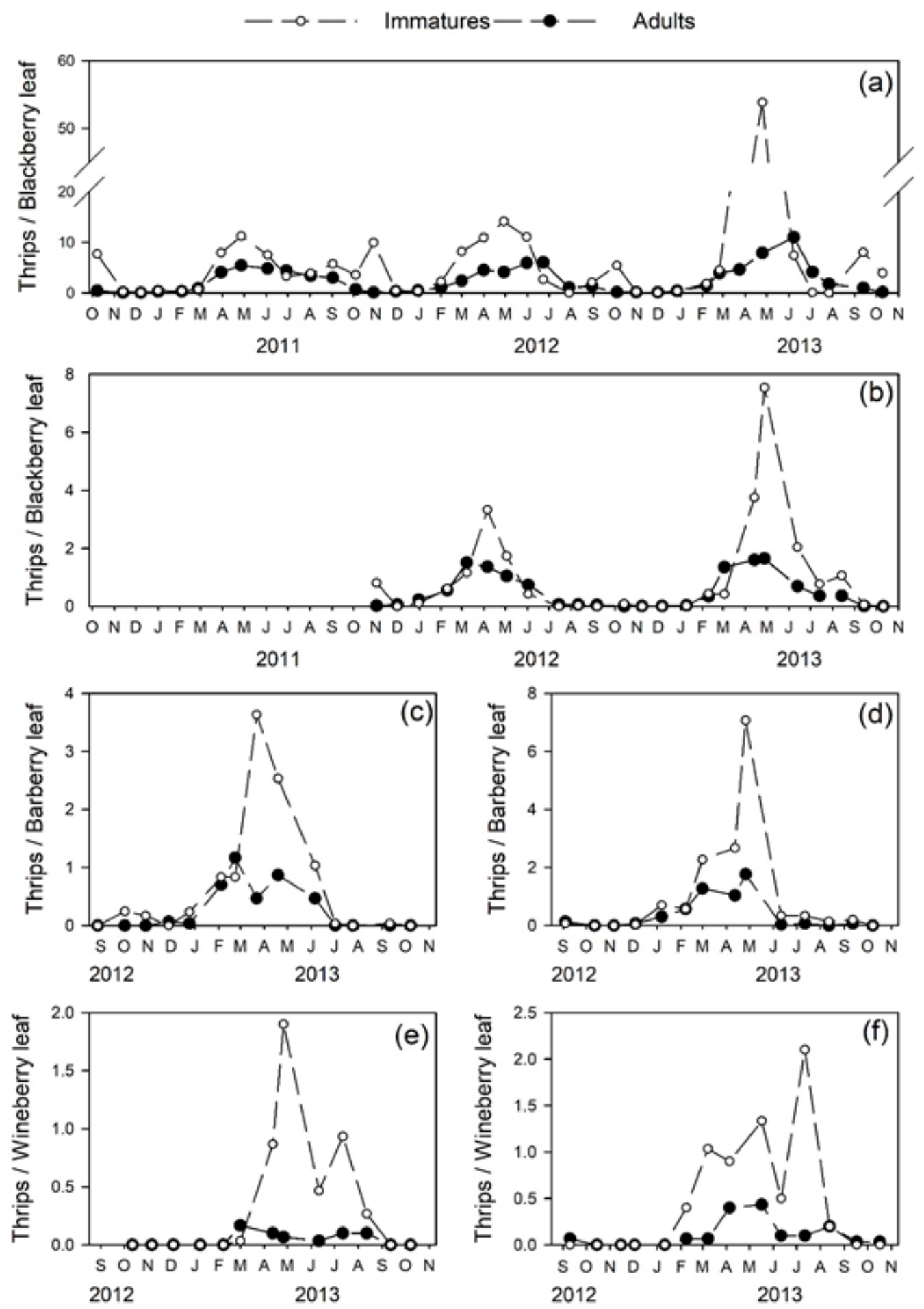

Figure 3 Phenology of adult (solid symbols) and immature (open symbols) greenhouse thrips, Heliothrips haemorrhoidalis, on blackberry leaves at (a) Site 1 and (b) Site 4, on barberry leaves at (c) Site 1 and (d) Site 4, and on wineberry leaves at (e) Site 4 and (f) Site 7. For blackberry and wineberry, the two sites with the highest abundance of thrips are shown.

\section{ACKNOWLEDGEMENTS}

This study was funded under the Strategic Science Investment Fund of Plant and Food Research during the years 2010-2013 and by Zespri Group Ltd through projects CP1757 Thrips risk from cryptomeria shelter (2017) and CP1858 Development of an IPM plan for greenhouse thrips (2018). Thanks to the Plant and Food Research science publishing office and colleagues Asha Chhagan and Lloyd Stringer, to Jessie Bong of Zespri Innovation and to the journal reviewers for editorial comments.

\section{REFERENCES}

Blank RH, Gill GS 1997. Thrips (Thysanoptera: Terebrantia) on flowers and fruit of citrus in New Zealand. New Zealand Journal of Crop and Horticultural Science 25: 319-332. https://doi.org/10.1080/01140671.1997.95 14023

Chhagan A, Stevens PS 2007. Effect of temperature on the development, longevity and oviposition of greenhouse thrips (Heliothrips haemorrhoidalis) on lemon fruit. 
New Zealand Plant Protection 60: 50-55. https://doi. org/10.30843/nzpp.2007.60.4608

Martin NA, Mound LA 2004. Host plants for some New Zealand thrips (Thysanoptera: Terebrantia). New Zealand Entomologist 27: 119-123. https://doi.org/10 $\underline{1080 / 00779962.2004 .9722133}$

Martin NA 2016. Distinguishing features of immature stages of Panchaetothripinae (Thysanoptera: Thripidae) known in New Zealand. New Zealand Journal of Zoology 43: 311-321.

Martin NA 2017. Host plants of Panchaetothripinae (Thysanoptera: Terebrantia: Thripidae) in New Zealand. New Zealand Journal of Zoology 44: 1-8. https://doi.org $\not 10.1080 / 03014223.2016 .1210652$

McKenna CE, Dobson SJ, Phare JM 2009. The insect pest complex of Actinidia arguta kiwifruit. New Zealand Plant Protection 62: 262-267. https://doi.org/10.30843/ nzpp.2009.62.4793

Mound LA, Walker AK 1982. Terebrantia (Insecta: Thysanoptera). Department of Scientific and Industrial Research, Wellington, Fauna of New Zealand 1,120 p.

Nakahara S, O’Donnell CA, Mound LA 2015. Heliothrips haemorrhoidalis and its relatives, with one new species and one new genus (Thysnaoptera: Thripidae). Zootaxa 4021: 578-584.

R Core Team 2019. A Language and Environment for Statistical Computing. R Foundation for Statistical Computing, Vienna, Austria

Rivnay E 1935. Ecological studies of the greenhouse thrips, Heliothrips haemorrhoidalis, in Palestine. Bulletin of Entomological Research 26: 267-278. https://doi. org/10.1017/S0007485300038207

Spiller DM, Wise KAJ 1982. A catalogue (1860-1960) of New Zealand insects and their host plants (Revised by P.S. Dale; P. A. Maddison), DSIR Science Information Division, Wellington $259 \mathrm{p}$.

Zondag R 1977. Heliothrips haemorrhoidalis (Bouche) (Thysanoptera: Thripidae), greenhouse thrips. Forest and Timber Insects in New Zealand No 24, New Zealand Forest Service, Rotorua. 